\title{
Phosphatidylinositol 3-kinase-dependent insulin regulation of long- chain fatty acid (LCFA) metabolism in L6 muscle cells: involvement of atypical protein kinase $C-\zeta$ in LCFA uptake but not oxidation
}

\author{
Karen R Kelly ${ }^{1}$, Chin K Sung ${ }^{3}$, Marcia J Abbott ${ }^{2}$ and Lorraine P Turcotte ${ }^{1,2}$ \\ ${ }^{1}$ Departments of Kinesiology and Biological Sciences, College of Letters, Arts, and Sciences, University of Southern California, 3560 Watt Way, PED 107, \\ Los Angeles, California 90089-0652, USA \\ Departments of ${ }^{2}$ Biological Sciences, College of Letters, Arts, and Sciences and ${ }^{3}$ Physiology and Biophysics, School of Medicine, University of Southern \\ California, Los Angeles, California 90033, USA \\ (Correspondence should be addressed to L P Turcotte; Email: turcotte@usc.edu)
}

\begin{abstract}
Insulin is important in the regulation of muscle metabolism. However, its role in the regulation of muscle long-chain fatty acid (LCFA) metabolism, independent of glucose, is not clear. To determine whether insulin regulates LCFA metabolism independent of glucose and if so, via which signaling pathway, L6 myotubes were incubated, in the presence or absence of insulin $(100 \mathrm{nM})$ and with either an inhibitor of phosphatidylinositol 3-kinase (PI3K) (wortmannin (W), $50 \mathrm{nM}$ ), protein kinase $\mathrm{B}(\mathrm{PKB}) / \mathrm{Akt}(\mathrm{A}, 10 \mu \mathrm{M})$, or atypical protein kinase $\mathrm{C}-\zeta(\mathrm{aPKC}-\zeta)(\mathrm{mP}, 100 \mu \mathrm{M})$. LCFA kinetic parameters were measured via incubation with $\left[1-{ }^{14} \mathrm{C}\right]$ palmitate. Basal LCFA uptake was found to increase linearly with time
\end{abstract}

(1-60 min) and concentration $(50-750 \mu \mathrm{M})$. LCFA uptake increased in the presence of insulin and was maximum at $10 \mathrm{nM}(P<0 \cdot 05)$. Wortmannin prevented the insulininduced increase in LCFA uptake and decrease in LCFA oxidation. While $\mathrm{mP}$ abolished the insulin-induced increase in LCFA uptake, it did not prevent the insulin-induced decrease in LCFA oxidation. None of the variables were affected by Akt inhibition. These results suggest a direct effect of insulin on LCFA metabolism in muscle cells, and that downstream of PI3K, aPKC- $\zeta$, but not PKB/Akt mediates the effects of insulin on LCFA uptake but not oxidation.

Journal of Endocrinology (2008) 198, 375-384

\section{Introduction}

It is well known that insulin affects skeletal muscle metabolism by increasing glucose uptake via GLUT-4 translocation from sarcolemmal vesicles to the plasma membrane (PM) and glycogen synthesis via activation of glycogen synthase (Salteil \& Kahn 2001). More recently, in muscle perfused or incubated with glucose, insulin has also been shown to decrease long-chain fatty acid (LCFA) oxidation, increase triacylglycerol (TG) synthesis, and increase LCFA uptake via translocation of the LCFA transporter, fatty acid translocase (FAT/CD36), from an intracellular compartment to the PM (Dyck et al. 2001, Luiken et al. 2002). However, the effects of insulin on muscle LCFA metabolism, independent of its stimulatory effects on glucose uptake and glycogen synthesis, have not been clearly defined.

It is well accepted that the effects of insulin on carbohydrate metabolism in skeletal muscle occur in large part via activation of phosphatidylinositol 3-kinase (PI3K) and other downstream molecules such as protein kinase $\mathrm{B} / \mathrm{Akt}$ (PKB/Akt) and

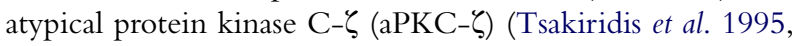
Yeh et al. 1995, Bandyopadhyay et al. 1997, Gonzalez \& Sanchez 2006). While it has been shown that PI3K is also part of the insulin-induced signaling cascade involved in the regulation of muscle LCFA metabolism (Dyck et al. 2001, Luiken et al. 2002), the signaling molecules located downstream of PI3K and responsible for the insulin-induced changes in LCFA metabolism are not known. Recently, insulin-mediated $\mathrm{PKB} / \mathrm{Akt}$ activation was found to be involved in the regulation of lipolysis via changes in the activation state of hormone-sensitive lipase (HSL) in adipose tissue (Gonzalez \& Sanchez 2006). Indeed, PKB/Akt was found to be the kinase responsible for the phosphorylation and activation of phosphodiesterase $3 \mathrm{~B}$ and for the concomitant decrease in cAMP levels, HSL activity, and TG breakdown (Degerman et al. 1998). Since it has been suggested that PKB/ Akt may be involved as a signaling molecule in the insulininduced pathway that regulates the insulin-mediated decrease in lipolysis in adipocytes, we aimed to determine whether $\mathrm{PKB} / \mathrm{Akt}$ might also be involved in the regulation of LCFA uptake and oxidation by insulin in muscle cells.

Likewise, aPKC- $\zeta$ is regarded as an important signaling molecule downstream of PI3K in the insulin signaling cascade in skeletal muscle (Koivisto et al. 1991, Bandyopadhyay et al. 1997, Sajan et al. 2006). This view is supported by evidence showing that impaired activation of aPKC- $\zeta$ in muscle of 
diabetic subjects (Beeson et al. 2005) and in myotubes of obese glucose-intolerant subjects (Vollenweilder et al. 2002, Watt et al. 2006) is associated with peripheral insulin resistance as measured by a decrease in insulin-sensitive glucose uptake and disposal. Because abnormalities in lipid metabolism have been directly linked to the development of insulin resistance (Kelley \& Mandarino 2000), it is imperative to determine the signaling molecules involved in the insulin-mediated regulation of LCFA metabolism in muscle. Combined with evidence showing that $\mathrm{aPKC}-\zeta$ mediates, at least in part, the effects of insulin on lipid synthesis in liver (Taniguchi et al. 2006), these results suggested that insulin might mediate its effects on LCFA metabolism via the aPKC- $\zeta$ pathway. Thus, we aimed to determine whether the insulin-mediated activation of aPKC- $\zeta$ is part of the insulin-induced signaling cascade that regulates LCFA uptake and oxidation in muscle cells.

Therefore, the primary purpose of this study was to determine whether insulin regulates LCFA metabolism, independent of glucose, in muscle cells and to gather evidence for the involvement of $\mathrm{PI} 3 \mathrm{~K}-\mathrm{PKB} / \mathrm{Akt}$ and/or $\mathrm{PI} 3 \mathrm{~K}-\mathrm{aPKC}-\zeta$ signaling in this regulation. L6 myotubes were employed in this study because it is widely recognized that cell culture systems offer unique advantages over intact muscle preparations including cell homogeneity and even accessibility to substrates and hormones. Furthermore, L6 myotubes are commonly used for muscle metabolism studies because they contain insulin receptors with its complement of signaling cascades, glucose, LCFA, and lactate transporter proteins, as well as metabolic enzymes and last but not least allow for an accurate measurement of LCFA uptake (Shainberg et al. 1971, Beguinot et al. 1986, Mitsumoto \& Klip 1992, Tsakiridis et al. 1995, Somwar et al. 1998, Hashimoto et al. 2006).

\section{Materials and Methods}

\section{Materials}

$\boldsymbol{\alpha}$-Minimal essential medium (MEM), fetal calf serum, and trypsin-EDTA were purchased from Cell Culture Facility (University of Southern California, Los Angeles, CA, USA). Antimycotic-antibiotic solution and wortmannin (W) were purchased from Sigma-Aldrich Ltd. The Akt inhibitor (A), 1L-6-hydroxymethyl-chiro-inositol 2-(R)-2-O-methyl3-O-octadecylcarbonate, and the aPKC- $\zeta$ inhibitor, myristoylated protein kinase $\mathrm{C}-\zeta$ pseudosubstrate $(\mathrm{mP})$, were purchased from CalBiochem (San Diego, CA, USA). Antibodies for phosphorylated acetyl-CoA carboxylase (ACC) $\left(\mathrm{Ser}^{79}\right)$, total ACC, phosphorylated phosphoinositol-dependent kinase-1 (PDK-1) $\left(\mathrm{Ser}^{241}\right)$, phosphorylated Akt $\left(\mathrm{Ser}^{473}\right)$, phosphorylated $\mathrm{PKC}-\zeta / \lambda\left(\mathrm{Thr}{ }^{410 / 403}\right)$, and anti-PKC- $\zeta$ were purchased from Cell Signaling Technologies (Beverly, MA, USA). Anti-Akt1/2 and GAPDH were purchased from Santa Cruz Biotechnologies Inc. (Santa Cruz, CA, USA) and CD36 was purchased from
Cascade Bioscience (Winchester, MA, USA) respectively. Purified polyclonal antibodies to anti-FABP ${ }_{\mathrm{PM}}$ were produced as described previously (Turcotte et al. 2002a,b), and have been used routinely by others and us (Kiens et al. 1997, Tucker \& Turcotte 2002, Turcotte et al. 2002a,b). Horseradish peroxidase (HRP) goat anti-rabbit secondary antibody and reagents (Super Signal West Pico) and film (CL-Xposure) for enhanced chemiluminescence (ECL) were purchased from Pierce (Rockford, IL, USA). Pork insulin was purchased from the University of Southern California Pharmacy (Los Angeles, CA, USA). Wako NEFA C test kit was purchased from Wako Chemicals (Richmond, VA, USA). $\left[1-{ }^{14} \mathrm{C}\right]$ palmitate was purchased from MP Biomedical (Irvine, CA, USA) and $\left[1-{ }^{14} \mathrm{C}\right]$ oleate, $\left[1-{ }^{14} \mathrm{C}\right]$ acetic acid, and $\left[{ }^{3} \mathrm{H}\right]-2$-deoxyglucose (2-DG) were purchased from Perkin-Elmer (Wellesey, MA, USA). Bradford reagent and gel electrophoresis supplies were from Bio-Rad.

\section{L6 cell culture}

L6 myotubes were cultured in $\alpha$-MEM+ containing $2 \%$ fetal calf serum and $1 \%$ antimycotic-antibiotic solution in a humidified incubator at $37^{\circ} \mathrm{C} / 5 \% \mathrm{CO}_{2}$. Cells were grown in $75 \mathrm{~cm}^{2}$ sterile culture flasks, sub-cultured at $60-80 \%$ confluence, split at a ratio of 1:10 using trypsin, and sub-cultured in 6-well dishes. By day 3, the cells were 100\% confluent and spontaneously differentiated into myotubes as verified by inverted phase contrast microscopy. For experiments, L6 myotubes that were 10 days post-confluent were used.

\section{Cell treatments}

Prior to all experimental treatments, cells were pre-incubated in serum-free medium for $90 \mathrm{~min}$ (except for glucose uptake, see below), followed by incubation in Krebs-Ringer-HEPES buffer (KRB) (1.47 mM K $2 \mathrm{HPO}_{4}, 140 \mathrm{mM} \mathrm{NaCl}, 1.7 \mathrm{mM}$ $\left.\mathrm{KCl}, 0.9 \mathrm{mM} \mathrm{CaCl}_{2}, 0.9 \mathrm{mM} \mathrm{MgSO}, 20 \mathrm{mM} \mathrm{HEPES}\right)$ for $30 \mathrm{~min}$. The cells were then pre-exposed either to the inhibitors (A, $10 \mu \mathrm{M} ; \mathrm{mP}, 100 \mu \mathrm{M}$; W, $50 \mathrm{nM}$ ) or vehicle (KRB) for $30 \mathrm{~min}$ prior to exposure to either insulin $(100 \mathrm{nM})$ or vehicle (KRB) for $15 \mathrm{~min}$ and $\left[1-{ }^{14} \mathrm{C}\right]$ palmitate bound to albumin $(100 \mu \mathrm{M})$ for $30 \mathrm{~min}$. All incubations took place at $37^{\circ} \mathrm{C}(95 \%$ $\mathrm{O}_{2} / 5 \% \mathrm{CO}_{2}$ ). The time and dose-response curves shown in Fig. $2 \mathrm{~A}$ and $\mathrm{B}$ were used to determine the duration of incubation and concentrations of insulin to be used for the experimental conditions. To characterize the insulin-induced signaling pathways involved in the regulation of LCFA metabolism, the effects of PI3K, PKB/Akt, and aPKC- $\zeta$ inhibition on insulin-mediated palmitate uptake and oxidation were determined. For each inhibitor, a dose-response curve was used to determine the optimal concentration for the measurement of palmitate uptake (Fig. 3A-C). For these experiments, L6 myotubes were pre-incubated in the presence or absence of W $(0-100 \mathrm{nM}), \mathrm{A}(0-50 \mu \mathrm{M})$, or $\mathrm{mP}(0-100 \mu \mathrm{M})$ or vehicle $(\mathrm{KRB})$ for $30 \mathrm{~min}$. This was followed by exposure to insulin $(100 \mathrm{nM})$ or vehicle $(\mathrm{KRB})$ for $15 \mathrm{~min}$ and $\left[1-{ }^{14} \mathrm{C}\right] \mathrm{pal}-$ mitate bound to albumin $(100 \mu \mathrm{M})$ for $30 \mathrm{~min}$. To eliminate the 
stimulatory effects of insulin on glucose uptake and glucose oxidation and the accompanying indirect effects on LCFA oxidation (Sidossis \& Wolfe 1996, Saha et al. 1997, Ueki et al. 1998), we eliminated glucose from the medium during incubations with metabolic inhibitors and/or insulin and during incubation with the experimental medium for the measurement of palmitate kinetics.

\section{Palmitate uptake}

Following inhibitor treatment and/or insulin exposure, the incubation medium was replaced with $1.0 \mathrm{ml}$ experimental medium $(100 \mu \mathrm{M}$ albumin-bound palmitate, 1:1) containing $\left[1-{ }^{14} \mathrm{C}\right]$ palmitate $(5 \mu \mathrm{Ci} / \mathrm{ml})$ for $30 \mathrm{~min}$, an incubation duration that has been shown to have no effect on insulin sensitivity in L6 cells (Sinha et al. 2004). Incubations were terminated by removing the media, and this was used to assay for ${ }^{14} \mathrm{C}$-labeled oxidation products (see below). Wells were washed twice with $\mathrm{KRB}$ and the cells were lysed with $0.05 \%$ SDS at room temperature for $30 \mathrm{~min}$ on a shaking orbitron. Duplicate $350 \mu \mathrm{l}$ aliquots of lysate were taken and mixed with scintillation fluid (BudgetSolve; Research Product International, Mount Prospect, IL, USA) and counted in a Tri-Carb liquid scintillation analyzer (model 2100TR; Packard, Meriden, CT, USA). Duplicate aliquots $(10 \mu \mathrm{l})$ of the same lysate were taken for protein determination using the Bradford method. Parallel studies were performed, in duplicate, using unlabelled palmitate bound to albumin $(1: 1)(100 \mu \mathrm{M})$ to determine the activation state of signaling molecules by western blotting.

\section{Palmitate oxidation}

To assay oxidation products, semi-dry filter paper (Whatman, Florham Park, NJ, USA) was glued to caps of vials and was saturated with $100 \mu \mathrm{l}$ ethanolamine, as described previously (Turcotte et al. 1999). Adaptations to the previously described protocol are as follows. Following the 30-min incubation with $\left[1-{ }^{14} \mathrm{C}\right]$ palmitate, duplicate aliquots of experimental media $(450 \mu \mathrm{l})$ were transferred to plastic scintillation vials containing $500 \mu \mathrm{l}$ of $70 \%(\mathrm{v} / \mathrm{v})$ perchloric acid and the caps were immediately placed on vials to trap released ${ }^{14} \mathrm{CO}_{2}$. After $24 \mathrm{~h}$, the caps were transferred to new vials containing ethylene glycol monomethyl ether to remove the filter paper. Toluene cocktail (1 M toluene, $22 \mathrm{mM}$ 2,5-diphenyloxazole (PPO), $0.82 \mathrm{mM}$ 1,4-bis (4-methyl-5-phenyl-oxazol-2benzene) (POPOP)) was added and ${ }^{14} \mathrm{CO}_{2}$ was counted via scintillation counting as described above.

To verify that our chosen incubation time of $30 \mathrm{~min}$ would not result in deleterious effects on insulin signaling and to demonstrate that there is no difference between the use of palmitate or oleate under our experimental conditions, additional cells were treated as described above and incubated with or without insulin $(100 \mathrm{nM})$ for $15 \mathrm{~min}$ followed by exposure to $\left[1-{ }^{14} \mathrm{C}\right]$ oleate for $30 \mathrm{~min}(\mathrm{~N}=12$ per condition). Oleate uptake and oxidation were measured as described above, and these values were compared with those obtained with $\left[1-{ }^{14} \mathrm{C}\right]$ palmitate.

To correct for carbon loss, additional experiments were conducted to determine the acetate correction factor under our experimental conditions (Sidossis et al. 1995, Tucker \& Turcotte 2002). Thus, in subsamples of cells $(n=3$ for each condition), the cells were treated as above except that $5 \mu \mathrm{Ci}$ $\left[1-{ }^{14} \mathrm{C}\right]$ acetate were added to the incubation medium rather than $\left[1-{ }^{14} \mathrm{C}\right]$ palmitate. The samples were taken as described above and analyzed for $\left[{ }^{14} \mathrm{C}\right]$ acetate and ${ }^{14} \mathrm{CO}_{2}$ radioactivities.

\section{Glucose uptake}

Cells were pre-incubated in serum-free medium for $5 \mathrm{~h}$ after which cells were washed twice with warm KRB buffer (Klip et al. 1984, Cross et al. 1994). Myotubes were either preexposed to $\mathrm{W}(50 \mathrm{nM})$ or vehicle (KRB) for $30 \mathrm{~min}$, and then incubated in the presence or absence of insulin $(100 \mathrm{nM})$ and/or W (50 nM) or vehicle (KRB) for $15 \mathrm{~min}$. Following exposure to insulin, insulin $+\mathrm{W}$ or vehicle, the cells were incubated in $200 \mu \mathrm{M} 2-\mathrm{DG}(0.5 \mu \mathrm{Ci} / \mathrm{ml})$ for $5 \mathrm{~min}$. Incubations were terminated via removal of the media. Individual wells were washed twice with KRB after which cells were lysed with $0.05 \%$ SDS at room temperature for $30 \mathrm{~min}$ on a shaking orbitron. Duplicate $350 \mu \mathrm{l}$ aliquots of lysate were taken for scintillation counting. Duplicate aliquots $(10 \mu \mathrm{l})$ of the same lysate were taken for protein determination using the Bradford method.

\section{Western blotting}

After the experimental treatment, cells were washed with ice-cold KRB. Lysis buffer was added $(20 \mathrm{mM}$ Tris, $1 \% \mathrm{~Np}-$ 40, $137 \mathrm{mM} \mathrm{NaCl}, 1 \mathrm{mM} \mathrm{CaCl}, 1 \mathrm{mM} \mathrm{MgCl}, 10 \%$ (v/v) glycerol, $1 \mathrm{mM}$ dithiothreitol, $1 \mathrm{mM}$ phenylmethylsulphonyl fluoride, $2 \mathrm{mM} \mathrm{Na}_{3} \mathrm{VO}_{4}$ ) and the cells were scraped to one side of the well. The lysates were transferred to microcentrifuge tubes, gently pelleted for $30 \mathrm{~min}$ at $4{ }^{\circ} \mathrm{C}$, and then spun at maximal speed of $15 \mathrm{~min}$. The supernatants were collected and aliquots $(10 \mu \mathrm{l})$ assayed for protein content (Bradford method). Cell supernatants were subjected to 7.5\% SDS-PAGE. The separated proteins were transferred onto Immobilon-P polyvinylidene difluoride (PVDF) membranes and blocked with 1\% BSA in Tween-TBS (TTBS; $500 \mathrm{mM} \mathrm{NaCl}, 20 \mathrm{mM}$ Tris, $0.05 \%$ Tween 20 (pH $7 \cdot 5))$ for $1 \mathrm{~h}\left(23^{\circ} \mathrm{C}\right)$ on a shaking orbitron, rinsed three times with TTBS, and incubated overnight with antibodies to either phospho-ACC $\left(\mathrm{Ser}^{79}\right)$ (1:1000), phosphorylated PDK-1 $\left(\operatorname{Ser}^{241}\right)$ (1:1000), phospho-Akt $\left(\mathrm{Ser}^{473}\right)$ (1:1000), Akt1/2 (1:1000), phospho-aPKC- $\zeta / \lambda\left(\right.$ Thr $\left.^{410 / 403}\right)(1: 1000)$, aPKC- $\zeta(1: 1000)$, or ACC $(1: 1000)$ at $4{ }^{\circ} \mathrm{C}$ with constant shaking. After further washing, the membranes were incubated with the secondary antibody HRP goat antirabbit $(1: 2000)$ for $1 \mathrm{~h}$ at room temperature, rinsed twice with TTBS, and once with TBS. The membranes were developed via ECL followed by exposure to Kodak 
X-OMAT film. Where appropriate membranes were stripped with $0.5 \mathrm{M} \mathrm{NaOH}$ for $15 \mathrm{~min}$ followed by a wash with TTBS for $5 \mathrm{~min}$, re-probed with GAPDH, and developed via ECL. The films were scanned using an HP Scanjet (6200C) and quantitated using Scion Image (Scion, Frederick, MD, USA). In all cases, multiple gels were analyzed and compared with control cells that had not been treated with any agents or insulin.

\section{Calculations and statistical analysis}

The rate of palmitate, oleate, and glucose uptake was calculated as the amount of radioactivity taken up by the cells in one well divided by the protein concentration (except where noted). The rate of palmitate oxidation was calculated as the amount of radioactivity recovered as ${ }^{14} \mathrm{CO}_{2}$ by the cells in one well divided by the protein concentration of the same well and corrected for label fixation using our determined acetate correction factor $(6 \cdot 22)$. All presented data are expressed as mean \pm s.E.M. and as \% control where control refers to cells that were not treated with insulin or inhibitors. Where appropriate, palmitate uptake and oxidation are expressed as \% control where $\%$ control was calculated as the difference between the experimental and control (usually basal conditions) rates (nmol/g per min) divided by the control rate (see figure legends for specific details). The effects of treatment with insulin and/or inhibitors were analyzed using Student's $t$-test or one-way ANOVA (StatSoft Statistica 6.0; Tulsa, OK, USA) followed by Fisher LSD post hoc test when appropriate. In all instances, $\alpha=0 \cdot 05$ was used to determine significance.

\section{Results}

Basal palmitate and oleate uptake and oxidation

As shown in Fig. 1, both LCFA transporter proteins, FAT/ CD36 and $\mathrm{FABP}_{\mathrm{PM}}$, were present in cell homogenates. Basal palmitate uptake was found to increase with palmitate concentration from 50 to $750 \mu \mathrm{M}(24 \cdot 8 \pm 3 \cdot 2$ to $249 \cdot 1 \pm$ $12 \cdot 0 \mathrm{nmol} / \mathrm{mg}$ for $30-\mathrm{min}$ incubation) and with time of incubation, from 1 to $60 \mathrm{~min}(2 \cdot 4 \pm 0 \cdot 1$ to $55 \cdot 7 \pm$ $3.6 \mathrm{nmol} / \mathrm{mg}$ for $100 \mu \mathrm{M}$ palmitate). Based on the linear dependency of palmitate uptake between 30 and $60 \mathrm{~min}$ and between 100 and $750 \mu \mathrm{M}$, we chose to carry out all other experiments for $30 \mathrm{~min}$ at a concentration of $100 \mu \mathrm{M}$.
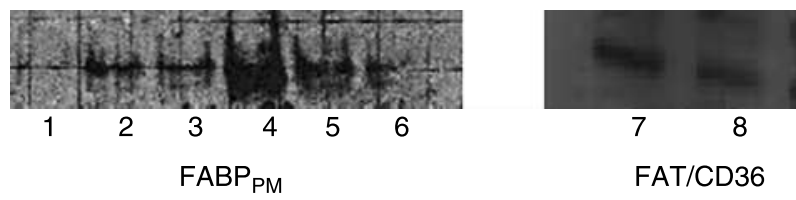

Figure 1 Western blot verifying the existence of $\mathrm{FABP}_{\mathrm{PM}}$ and FAT/CD36 in L6 cells. Lanes 1-6 represent L6 cells at 0, 2, 4, 10, 17, and 34 days post-confluence, and lanes 7 and 8 represent L 6 cells at 10 days post-confluence.
Comparison of uptake and oxidation data between palmitate and oleate showed that both LCFA can be used as representative LCFA under our experimental conditions. LCFA uptake and oxidation rates calculated with ${ }^{14} \mathrm{C}$-palmitate and ${ }^{14} \mathrm{C}$-oleate are within the range of values observed by others (Palanivel \& Sweeney 2005, Dimopoulos et al. 2006, Watt et al. 2006). Most importantly, our data showed that the percent increase in LCFA uptake $(25 \pm 0.8$ vs $29.4 \pm 1.3 \%$ in palmitate- and oleate-treated cells respectively) and percent decrease in LCFA oxidation $(26 \pm 0 \cdot 3$ vs $28 \pm 0 \cdot 8 \%$ respectively) observed with insulin stimulation were not significantly different between the two LCFA groups. This showed that the insulin effect was similar between LCFA. We chose to use ${ }^{14} \mathrm{C}$-palmitate because its basal rates of uptake and oxidation were higher and this makes it easier to measure experimental changes.

\section{Glucose and palmitate uptake and oxidation}

To provide evidence that our cell system responds in a manner similar to L6 cell systems used by other research teams, we measured glucose uptake both in the control state and after insulin stimulation. As shown repeatedly by others (Bilan et al. 1991, Tsakiridis et al. 1995), insulin significantly $(P<0 \cdot 05)$ increased glucose uptake by $30 \%$ when compared with the rate measured under control condition $(554 \cdot 1 \pm 14 \cdot 0$ vs $429.9 \pm 4.2 \mathrm{nmol} / \mathrm{g}$ per $\mathrm{min})$. Furthermore, pretreatment with W completely abolished insulin-stimulated glucose uptake so that glucose uptake was not different from the rate measured under control condition $(429 \cdot 9 \pm 4 \cdot 2$ vs $371 \cdot 3 \pm 6 \cdot 4 \mathrm{nmol} / \mathrm{g}$ per $\min , P>0 \cdot 05)$.

Time and dose-response curves for insulin-stimulated palmitate uptake

Insulin, independent of glucose, significantly $(P<0 \cdot 05)$ increased palmitate uptake in L6 myotubes and the insulininduced increase $(25 \%)$ was maximum at an insulin concentration of $1.0 \mathrm{nM}$ (or $1 \times 10^{-9} \mathrm{M}$ which is represented as $\log \left[1 \times 10^{-9}\right] \mathrm{M}$ or 9 in Fig. 2A). Furthermore, to determine whether the effects of insulin were time dependent, cells were exposed to $100 \mathrm{nM}$ insulin for increasing time periods, ranging from 0 to $60 \mathrm{~min}$. Insulin-stimulated palmitate uptake showed a biphasic response, reaching maximal values $(P<0 \cdot 05)$ at 5 and 15 min of incubation and lower values after prolonged exposure to insulin (30 and $60 \mathrm{~min}$ ) (Fig. 2B). Therefore, to ensure maximal stimulation by insulin and for comparison purposes with other studies that typically use $100 \mathrm{nM}$ insulin to stimulate the cells (Bilan et al. 1991, Lin et al. 2001), we opted to treat the cells with $100 \mathrm{nM}$ insulin for $15 \mathrm{~min}$ for the remaining experiments.

\section{Palmitate uptake and oxidation and insulin signaling pathway}

To better characterize the insulin-induced signaling molecules involved in the regulation of insulin-mediated 

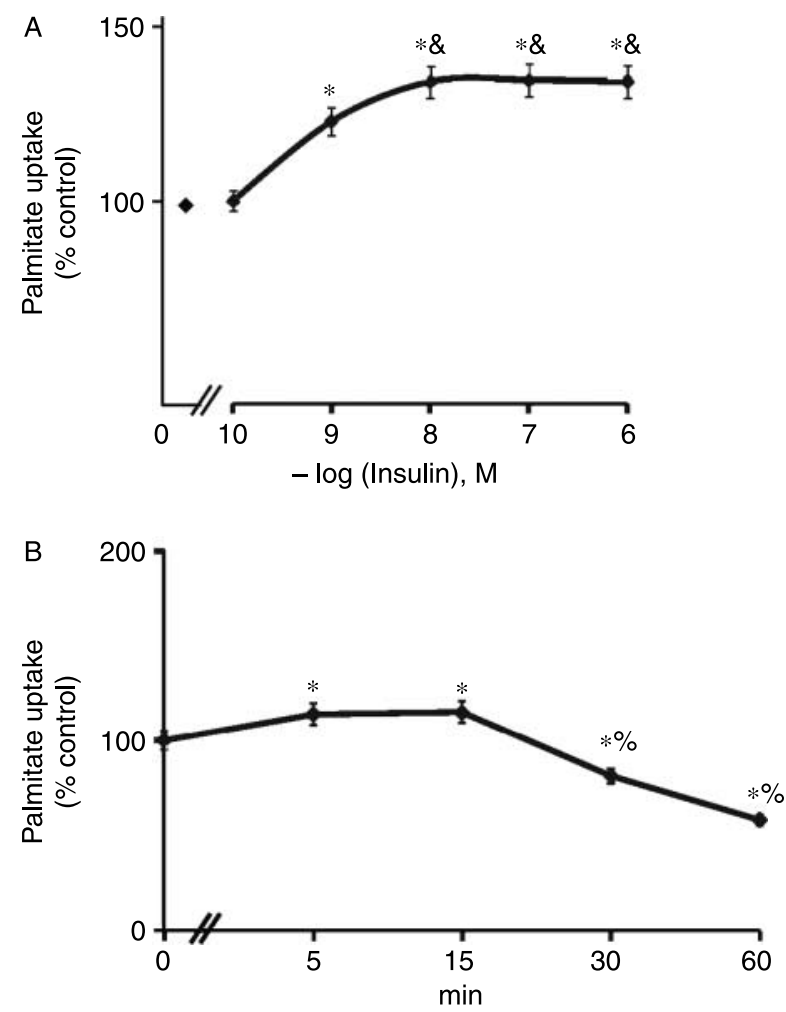

Figure 2 (A) Dose-response and (B) time-response curves for insulin on palmitate uptake in L6 myotubes. Cells were exposed to (A) insulin (0-1000 $\mathrm{nM}$ ) for $15 \mathrm{~min}$ or (B) $100 \mathrm{nM}$ insulin for various durations (0-60 min). Palmitate uptake was measured as described in. Data are presented as means \pm S.E.M. ( $n=9$ per condition) and expressed as '\% control' where control refers to cells not treated with insulin. ${ }^{*} P<0.05$ versus control or zero for both $(A)$ and $(B)$; ${ }^{\&} P<0.05$ vs $0,0.1$ and $1 \mathrm{nM} ;{ }^{\%} P<0.05$ vs 5 and $15 \mathrm{~min}$.

palmitate uptake and oxidation, PI3K, PKB/Akt, and aPKC- $\zeta$ were inhibited. Whereas PI3K inhibition with W prevented the insulin-induced increase in palmitate uptake at all three doses (Fig. 3A), PKB/Akt inhibition with A had no effect on insulin-mediated palmitate uptake at any of the doses used (Fig. 3B). aPKC- $\zeta$ inhibition with $\mathrm{mP}$ had no effect on insulin-mediated palmitate uptake at the lowest dose used (Fig. 3C). However, at higher doses $(50$ and $100 \mu \mathrm{M}), \mathrm{mP}$ completely inhibited insulin-mediated palmitate uptake such that palmitate uptake was not different from their respective control conditions. To ensure that insulin stimulation activated PKB-Akt and aPKC- $\zeta$, the phosphorylation state of these signaling molecules was measured by western blotting. $\mathrm{PKB} / \mathrm{Akt}$ and aPKC- $\zeta$ protein content was not affected by treatment with insulin and/or any of the inhibitors (Fig. 4A). As shown by others (Bandyopadhyay et al. 1997, Hajduch et al. 1998), the phosphorylation state of PKB/Akt was increased with insulin, inhibited by both $\mathrm{W}$ and $\mathrm{A}$, and was not affected by pre-incubation with the aPKC- $\zeta$ inhibitor $(\mathrm{mP})$ (Fig. 4B), suggesting that the $\mathrm{mP}$ compound did not interfere with insulin stimulation of PKB/Akt. Similarly, the phosphorylation state of aPKC- $\zeta$ was increased by insulin, inhibited by both $\mathrm{W}$ and $\mathrm{mP}$, and was not affected by preincubation with A (Fig. 4C). Furthermore, insulin increased PDK-1 activity as evidenced by an increase in its phosphorylation state and treatment with $\mathrm{W}$ prevented insulinstimulated phosphorylation (Fig. 4D). Neither A nor mP affected the insulin-induced phosphorylation state of PDK-1. Based on the data from the dose-response curves and western blot analysis, we chose to pre-incubate the cells with $50 \mathrm{nM}$ $\mathrm{W}, 10 \mu \mathrm{M} \mathrm{A}$, and $100 \mu \mathrm{M} \mathrm{mP}$ for all other experiments as these concentrations maximally and specifically inhibit our target signaling molecules.

Using those selected inhibitor concentrations, our results show that inhibition of PI3K and aPKC- $\zeta$ completely abolished the insulin-induced increase in palmitate uptake such that palmitate uptake was not different from the basal rate (Fig. 5A). Conversely, PKB/Akt inhibition had no effect on the insulin-induced increase in palmitate uptake $(P>0.05$ versus insulin only condition). Furthermore, insulin significantly decreased palmitate oxidation by $29 \%(31 \cdot 8 \pm 2 \cdot 4$ to $24.7 \pm 1.6 \mathrm{nmol} / \mathrm{g}$ per min) $(P<0 \cdot 05)$ (Fig. 5B). Inhibition of PI3K abolished the insulin-induced decrease in palmitate oxidation such that palmitate oxidation was not different from control ( $P>0.05)$, while PKB/Akt inhibition did not prevent the insulin-induced decrease in palmitate oxidation (Fig. 5B). In contrast to insulin-induced palmitate uptake, aPKC- $\zeta$ inhibition did not prevent the insulin-induced decrease in palmitate oxidation $(P<0 \cdot 05$ versus control). Because the phosphorylation state of $\mathrm{PKB} / \mathrm{Akt}$ under insulin-stimulated conditions was not affected by pre-incubation with $\mathrm{mP}$ (Fig. 4B), our results show that aPKC- $\zeta$ inhibition with $\mathrm{mP}$ did not prevent insulin from stimulating PKB/Akt activity. To provide a possible mechanism of action for the insulin-induced decrease in palmitate oxidation, we measured the phosphorylation state of ACC. Our data showed that ACC phosphorylation (C, $100 \pm 5 \cdot 2$ vs I, $80 \pm 15$ arbitrary units) or total ACC protein was not affected by insulin (Fig. 6A and B).

\section{Discussion}

Our experiments provide extensive information about the effects of insulin, independent of its effects on glucose uptake and metabolism, on LCFA metabolism in muscle cells and, more importantly, provide novel information about the signaling molecules involved in the regulation of LCFA uptake and oxidation by insulin. Our data show that insulin, independent of glucose, directly stimulates LCFA uptake and inhibits LCFA oxidation via the PI3K-dependent insulin signaling pathway. Furthermore, our results show, for the first time, that aPKC- $\zeta$, a signaling molecule located downstream of PI3K, is involved in the regulation of insulin-induced LCFA uptake. This notion is supported by our results that show parallel changes in aPKC- $\zeta$ activation and LCFA uptake with insulin stimulation and $\mathrm{AKC}-\zeta$ inhibition. Interestingly, while our results show that the insulin-induced inhibition of 
LCFA oxidation is also mediated via a PI3K-dependent signaling pathway; our data suggest that $\mathrm{PKB} / \mathrm{Akt}$ and $\mathrm{aPKC}-$ $\zeta$ are not the primary signaling intermediates involved in this insulin-induced regulation of LCFA oxidation.

Our results show that in L6 muscle cells incubated without glucose insulin stimulation increases LCFA uptake in a time- and
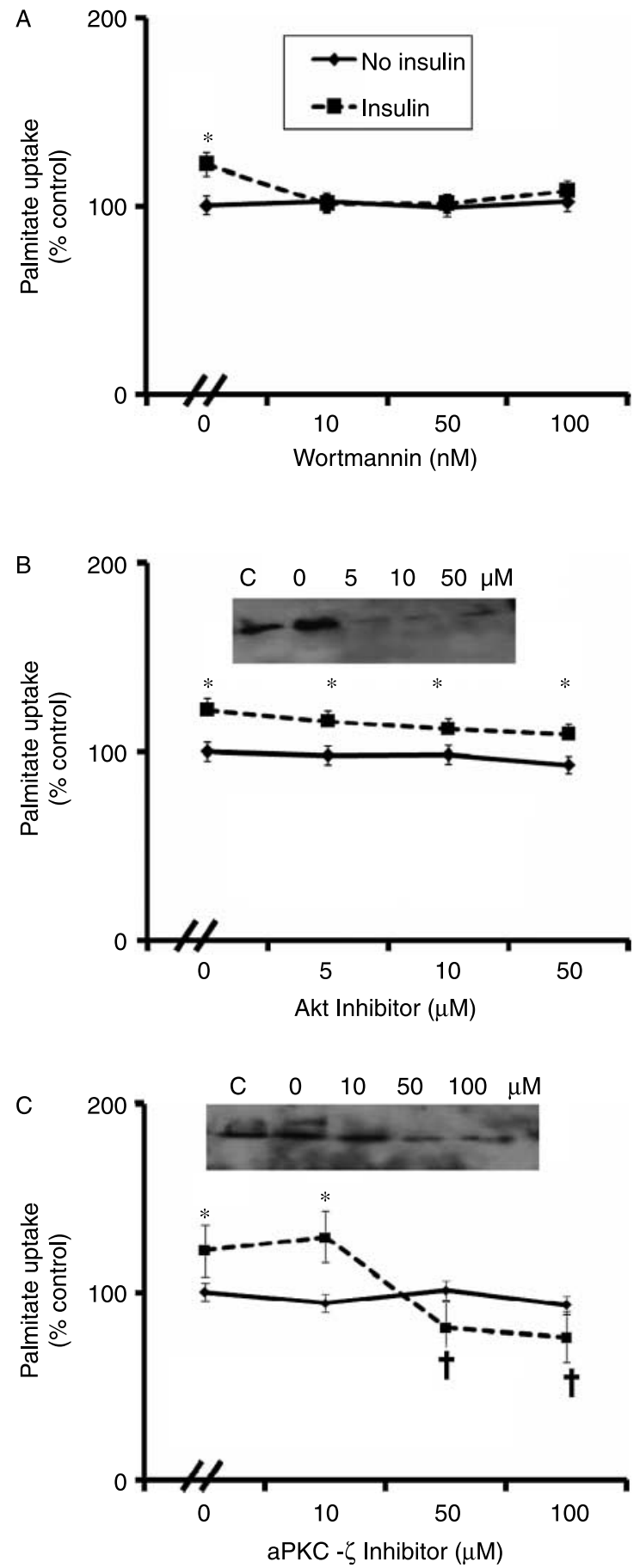

concentration-dependent manner. While several authors have shown previously that insulin increases LCFA uptake in incubated or perfused muscle (Muoio et al. 1999, Dyck et al. 2001, Luiken et al. 2002), it was not clear from those results whether insulin per se was responsible for the observed changes in LCFA metabolism or whether the accompanying stimulatory effect of insulin on glucose uptake and metabolism was in part responsible for the measured changes. It is also interesting to note that prolonged incubation with insulin resulted in a decrease in insulin-induced LCFA uptake. These results were not unexpected since exposure to insulin for similar durations (1-8 h) has been shown to decrease glucose uptake by $20-40 \%$ in perfused rat hindquarter and incubated muscle cells (Beguinot et al. 1986, Richter et al. 1988, Koivisto et al. 1991). As discussed by Richter et al. (1988), the decrease in insulin action may reflect the development of an insulin-resistant state.

The secondary aim of this study was to gather preliminary information on signaling molecules that may be involved in the regulation of LCFA uptake and oxidation by insulin. Because several of the metabolic actions of insulin on cellular metabolism have been shown to occur via stimulation of insulin receptor substrate-1-associated PI3K activity (Farese 2001) and because data collected in incubated and perfused muscle showed that PI3K might be involved as a downstream signaling molecule in the insulin-induced pathway that regulates LCFA metabolism (Muoio et al. 1999, Dyck et al. 2001, Luiken et al. 2002), we first determined whether PI3K activation was similarly involved in the regulation of LCFA metabolism by insulin in L6 muscle cells. In agreement with these previous results, our data show that pre-incubation of L6 muscle cells with the PI3K inhibitor wortmannin prevents the insulin-induced increase in LCFA uptake and decrease in LCFA oxidation, and that insulin-induced LCFA uptake is completely inhibited at concentrations as low as $10 \mathrm{nM}$ of wortmannin. This is similar to results of Yeh et al. (1995) and Somwar et al. (1998) who found that inhibition of hexose uptake in muscle via wortmannin was concentration dependent with an $\mathrm{IC}_{50}$ occurring around $10-30 \mathrm{nM}$.

PI3K has been shown to activate both $\mathrm{PKB} / \mathrm{Akt}$ and aPKC- $\zeta$, two signaling molecules, which are located

Figure 3 Inhibitor dose-response curves with representative western blot for (A) wortmannin, (B) inhibitor $\mathrm{A}$, and (C) $\mathrm{mP}$ on palmitate uptake in L6 myotubes. For inhibitor efficacy, cells were exposed to varying inhibitor concentrations for $30 \mathrm{~min}$ followed by insulin (100 nM) or KRB for 15 min. Palmitate uptake was measured for $30 \mathrm{~min}$ as described in Methods. Gel panels above figure B, C show the effects of increasing concentrations of $(B)$ inhibitor $A$ and (C) $\mathrm{mP}$ on Akt and aPKC- $\zeta$ phosphorylation. Data are presented as means \pm S.E.M. ( $n=6$ per condition per curve) and as ${ }^{\prime} \%$ control' $^{\prime}$ where for the 'no insulin' conditions, control cells were not treated with inhibitor or insulin and were paired to the cells treated with inhibitor only and 'insulin' cells; control cells are those that have been treated with inhibitor but not insulin and were paired with cells treated with inhibitors and insulin. ${ }^{*} P<0.05$ versus no insulin control. ${ }^{+} P<0.05$ versus insulin plus 0 and $10 \mu \mathrm{M} \mathrm{mP}$. A, Akt/PKB inhibitor; $\mathrm{mP}$, aPKC inhibitor. 
A

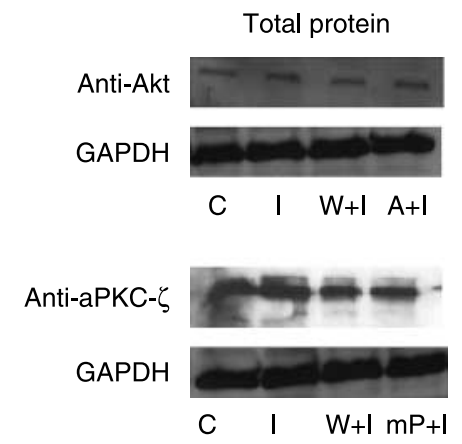

B

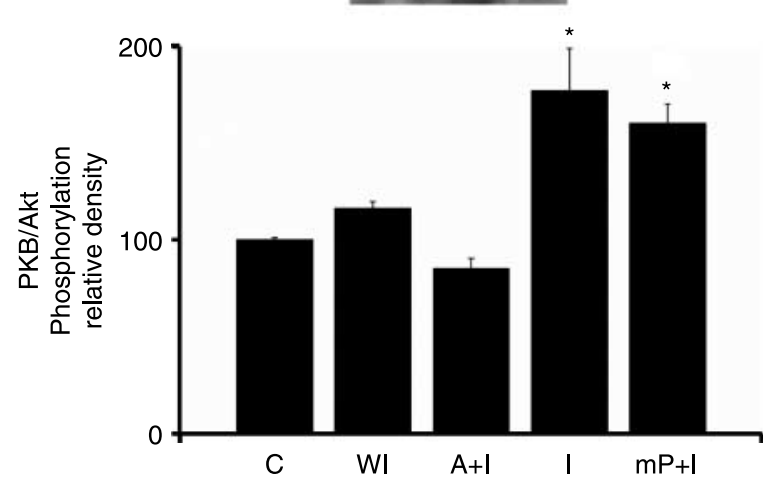

C

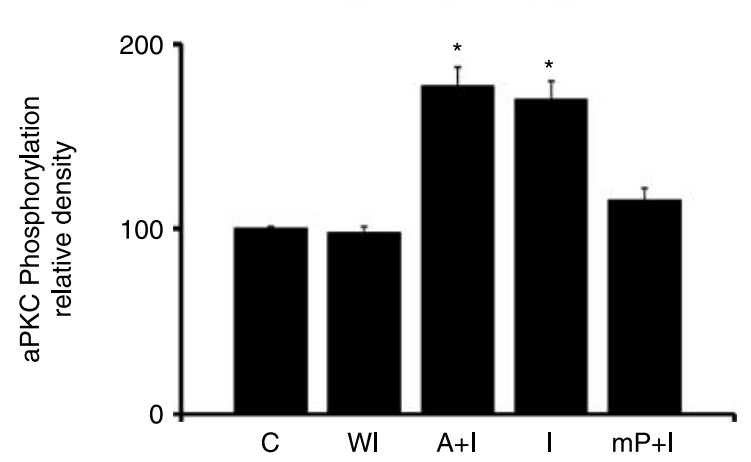

D

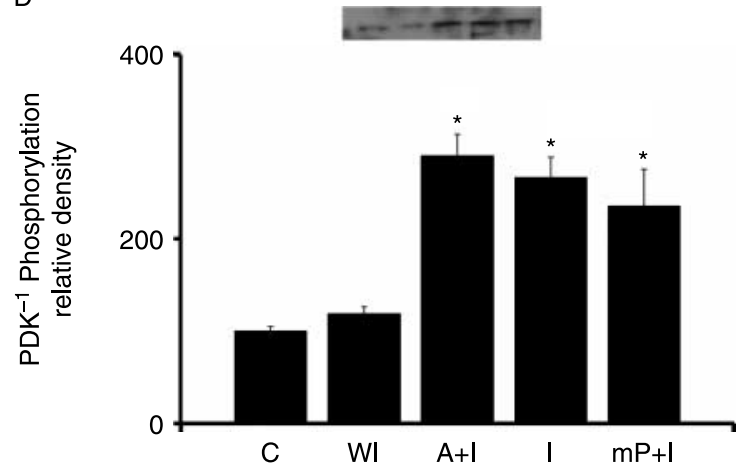

downstream of PI3K and which have been shown to be dependent upon PDK-1 for activation (Valverde et al. 2000, Farese 2001, Beeson et al. 2005, Farese et al. 2005). Our PDK-1 results are in agreement with the suggestion that PDK-1 lies downstream of PI3K and could possibly be a branching point for distal signaling pathways, such as Akt/ PKB and aPKC- $\zeta$ (Salteil \& Kahn 2001, Scheid \& Woodgert 2003, Sajan et al. 2006, Farese et al. 2005). PKB/Akt has been proposed to mediate some of the cellular effects of insulin since overexpression of this signaling molecule in L6 muscle cells was shown to mimic the stimulatory actions of insulin on glucose uptake, GLUT-4 translocation to the PM, and glycogen synthesis (Hajduch et al. 1998, Ueki et al. 1998). However, our data show that PKB/Akt inhibition in L6 cells did not prevent the insulin-induced increase in LCFA uptake or decrease in LCFA oxidation and increasing the concentrations of the Akt inhibitor in the incubation medium did not change the rates of insulin-induced LCFA uptake and oxidation. Our results agree with those of Bouzakri et al. (2006) who showed that Akt1 and Akt2 silencing did not prevent the stimulatory effects of insulin on LCFA uptake nor the inhibitory effects of insulin on LCFA oxidation. As suggested by Bouzakri et al. (2006), our data show that $\mathrm{PKB} / \mathrm{Akt}$ may be dispensable for the regulation of insulinmediated LCFA uptake and oxidation in muscle cells.

A novel finding of our study is the involvement of aPKC- $\zeta$ in the regulation of insulin-mediated LCFA uptake. Direct inhibition of $\mathrm{aPKC}-\zeta$ with an isoform-specific inhibitor commonly used in metabolic studies (Bandyopadhyay et al. 1997, Chabowski et al. 2004) completely abolished the insulininduced increase in LCFA uptake and this effect was concentration dependent. As reported by others in cardiac myocytes (Chabowski et al. 2004), pre-incubation with a low concentration $(10 \mu \mathrm{M})$ of the $\mathrm{aPKC}-\zeta$ inhibitor did not affect insulin-induced LCFA uptake. However, when the concentration of the inhibitor was increased to 50 or $100 \mu \mathrm{M}$, the rate of insulin-induced LCFA uptake was returned to control level demonstrating the effectiveness of the inhibitor in reducing insulin signaling. This is in agreement with findings that report an $\mathrm{IC}_{50}$ of $48 \mu \mathrm{M}$ for this aPKC- $\zeta$ inhibitor with respect to insulin-stimulated glucose uptake (Bandyopadhyay et al. 1997). While aPKC- $\zeta$ inhibition prevented LCFA uptake, there was no effect on LCFA oxidation, suggesting that other signaling

Figure 4 Effect of insulin and $\mathrm{PI} 3 \mathrm{~K}, \mathrm{PKB} / \mathrm{Akt}$, or aPKC- $\zeta$ inhibition on phosphorylation of downstream signaling molecules in L6 myotubes. Cells were exposed to inhibitors W $(50 \mathrm{nM}), \mathrm{A}(10 \mu \mathrm{M})$, and $\mathrm{mP}(100 \mu \mathrm{M})$ or KRB for 30 min followed by insulin $(100 \mathrm{nM})$ or $\mathrm{KRB}$ for $15 \mathrm{~min}$ and palmitate $(100 \mu \mathrm{M})$ for $30 \mathrm{~min}$. The cells were lysed and prepared for western blotting with (A) anti-Akt or antiaPKC- $\zeta$ (and striped and re-probed with GAPDH for control purposes) to assess total protein content that was not affected by any of the experimental conditions (see Results section), (B) phosphorylated Akt $\left(\mathrm{Ser}^{473}\right),(\mathrm{C})$ phosphorylated aPKC- $\zeta / \lambda$ $\left(\mathrm{Thr}^{410 / 403}\right)$, or (D) phosphorylated PDK-1 $\left(\mathrm{Ser}^{241}\right)$. Data are presented as means \pm S.E.M. ( $n=6$ per condition). ${ }^{*} P<0 \cdot 05$ versus control and insulin plus inhibitor conditions. W, PI3K inhibitor, wortmannin; A, Akt/PKB inhibitor; $\mathrm{mP}$, aPKC inhibitor. 

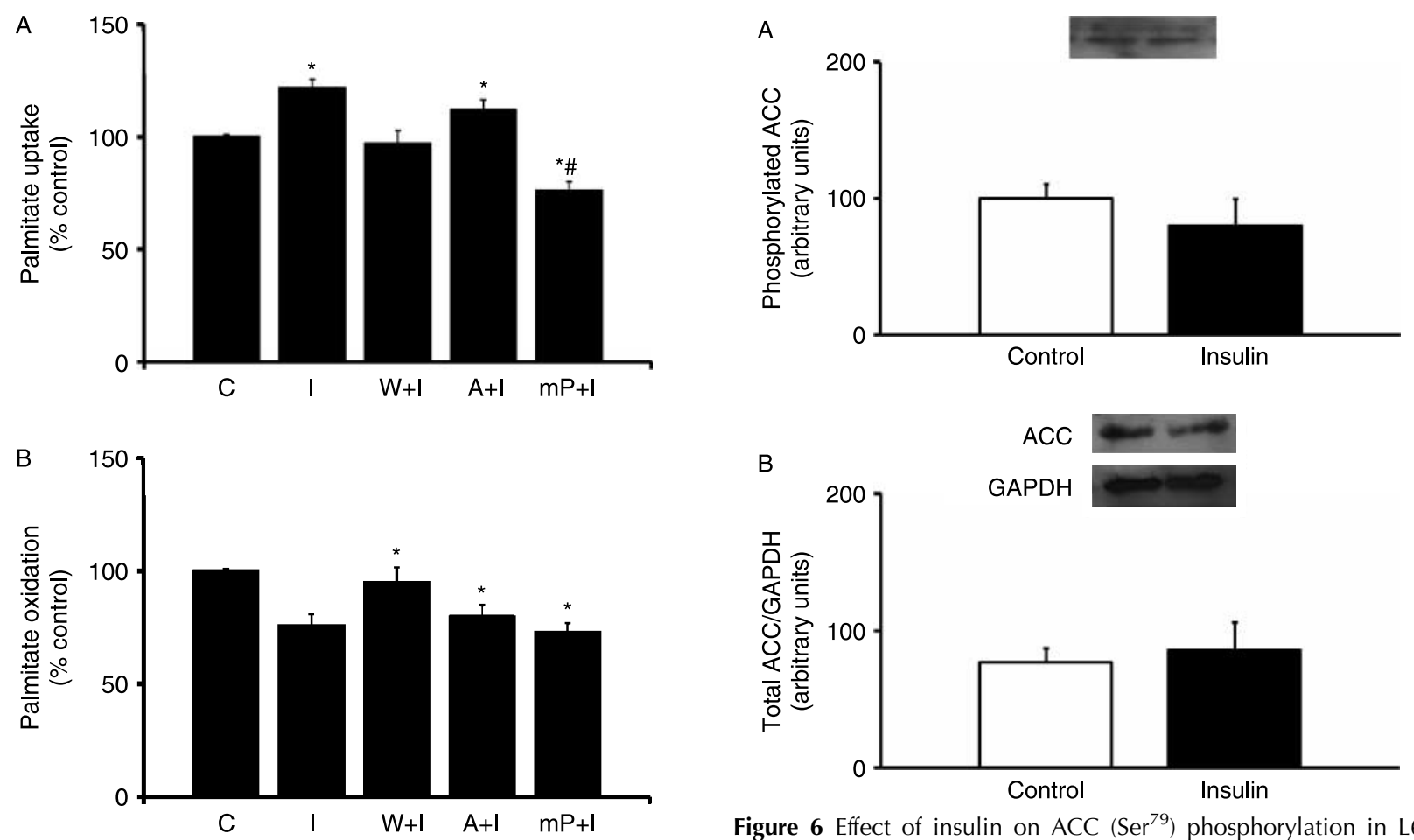

Figure 5 Effect of insulin and $\mathrm{PI} 3 \mathrm{~K}, \mathrm{Akt} / \mathrm{PKB}$, or aPKC $\zeta$ inhibition on (A) palmitate uptake and (B) oxidation in L6 myotubes. Cells were exposed to inhibitors $\mathrm{W}(50 \mathrm{nM}), \mathrm{A}(10 \mu \mathrm{M})$, and $\mathrm{mP}(100 \mu \mathrm{M})$ or $\mathrm{KRB}$ for $30 \mathrm{~min}$ followed by insulin $(100 \mathrm{nM})$ or KRB for 15 min and $\left[{ }^{14} \mathrm{C}\right]$ palmitate $(100 \mu \mathrm{M})$ for $30 \mathrm{~min}$. Palmitate uptake and oxidation were measured as described in Methods. Data are presented as means \pm S.E.M. ( $n=12-18$ per condition, $n=6$ per condition per curve); and as '\% control' where control refers to paired cells not treated with insulin. ${ }^{*} P<0 \cdot 05$ versus control (no insulin, no inhibitors); ${ }^{\#} P<0.05$ versus insulin only. W, PI3K inhibitor, wortmannin; A, Akt/PKB inhibitor; $\mathrm{mP}$, aPKC inhibitor.

mechanisms may be mediating these effects. It is known that the MAPK/ERK1/2 pathway is involved in insulin signaling and may mediate some of the effects of insulin on intracellular lipid metabolism. Indeed, our laboratory has recently demonstrated that ERK1/2 is involved in the regulation of contractioninduced changes in LCFA metabolism (Raney \& Turcotte 2007). Whether ERK1/2 activation plays a similar regulatory role during insulin stimulation in L6 cells is not known. Finally, it might also be argued that the insulin-mediated decrease in LCFA oxidation is regulated metabolically via changes in enzyme activity. It has been shown by some (Witters \& Kemp 1992, Gamble \& Lopaschuk 1997) but not others (Winder \& Holmes 2000) that insulin activates ACC. In line with a welldocumented chain of metabolic events, ACC stimulation would be associated with high intracellular malonyl-CoA and inhibition of carnitine palmitoyltransferase-1 and ultimately lead to a decrease in LCFA oxidation. However, our ACC data show that under our experimental conditions, metabolic regulation of insulin-mediated LCFA oxidation via this scenario was not significant.

Figure 6 Effect of insulin on ACC $\left(\mathrm{Ser}^{79}\right)$ phosphorylation in L6 myotubes. Cells were exposed to insulin $(100 \mathrm{nM})$ for 15 min prior to exposure to unlabelled palmitate $(100 \mu \mathrm{M})$ for $30 \mathrm{~min}$. Cells were lysed and prepped for western Blot with (A) phosphorylated ACC $\left(\mathrm{Ser}^{79}\right)$ and $(\mathrm{B})$ total ACC. Total ACC membranes were stripped and re-probed with GAPDH as described in Methods. Data are presented as arbitrary units \pm S.E.M. ( $n=4$ gels per condition).

In conclusion, our results demonstrate for the first time that insulin, independent of glucose, increases LCFA uptake and decreases LCFA oxidation via insulin-induced PI3K signaling in muscle cells. Furthermore, our data show that insulin exerts its stimulatory effect on LCFA uptake via the PI3K-aPKC- $\zeta$ branch of the insulin-PI3K signaling cascade. While our data are based on the information obtained using chemical inhibitors and cannot be used exclusively and absolutely as proof of our hypothesis, our results suggesting the involvement of aPKC- $\zeta$ in the regulation of LCFA uptake by insulin points the direction for future, more sophisticated, studies utilizing constitutively active and inactive kinases and/or siRNA.

\section{Declaration of Interest}

The authors declare that there is no conflict of interest that would prejudice the impartiality of this scientific work.

\section{Funding}

This research was funded in part by the Women in Sciences and Engineering (WiSE) and the Zumberge Research and Innovation Fund (ZRIF) programmes of the University of Southern California, the National Institutes of Health (no. AR45-168), and the Student Research Awards from the 
National and Southwest Chapter (Norman James Award) of the American College of Sports Medicine.

\section{Acknowledgements}

We would like to thank Melanie $\mathrm{T}$ Cheng for her valuable laboratory assistance.

\section{References}

Bandyopadhyay G, Standaert M, Galloway L, Moscat J \& Farese R 1997 Evidence for involvement of protein kinase $\mathrm{C}$ (PKC)- $\zeta$ and noninvolvement of diacylglycerol-sensitive PKCs in insulin-stimulated glucose transport in L6 myotubes. Endocrinology 138 4721-4731.

Beeson M, Sajan M, Dizon M, Grebenev D, Gomez-Daspet J, Miura A, Kanoh Y, Powe J, Bandyopadhyay G, Standaert M et al. 2005 Activation of protein kinase $\mathrm{C}-\zeta$ by insulin and phosphatidylinositol-3,4,5-( $\left.\mathrm{PO}_{4}\right) 3$ is defective in muscle in type 2 diabetes and impaired glucose tolerance. Diabetes 52 1926-1934.

Beguinot F, Kahn R, Moses A \& Smith R 1986 The development of insulin receptors and responsiveness is an early marker of differentiation in the muscle cell line L6. Endocrinology 18 446-455.

Bilan P, Ramlal T \& Klip A 1991 In IGF-1 mediated recruitment of glucose transporters form intracellular membranes to the plasma membranes in L6 muscle cells, pp 273-288. Eds MK Raizada \& D LeRoith. New York: Plenum Press.

Bouzakri K, Zachrisson A, Al-Khalili L, Zhang B, Koistinen H, Krook A \& Zierath J 2006 siRNA-based gene silencing reveals specialized roles of IRS1/Akt2 and IRS 2/Akt1 in glucose and lipid metabolism in human skeletal muscle. Cellular Metabolism 4 89-96.

Chabowski A, Coort S, Calles-Escandon J, Tandon N, Glatz J, Luiken J \& Bonen A 2004 Insulin stimulates fatty acid transport by regulating expression of FAT/CD36 but not FABP $_{\mathrm{PM}}$. American Journal of Physiology. Endocrinology and Metabolism 287 781-789.

Cross D, Alessi D, Vandenheede J, McDowell H, Hundal H \& Cohen P 1994 The inhibition of glycogen synthase kinase 3 by insulin or insulin like growth factor 1 in the rat skeletal muscle cell line L6 is blocked by wortmannin, but not by rapamycin: evidence that wortmannin blocks activation of the mitogen-activated protein kinase pathway in L6 cells between Ras and Raf. Journal of Biological Chemistry 303 21-26.

Degerman E, Landstrom T, Wijkander J, Holst L, Ahmad F, Belfrage P \& Manganiello V 1998 Phosphorylation and activation of hormone sensitive adipocyte phosphodiesterase type 3B. Methods 14 43-53.

Dimopoulos N, Watson M, Sakamoto K \& Hundal HS 2006 Differential effects of palmitate and palmitoleate on insulin action and glucose utilization in rat L6 skeletal muscle cells. Biochemical Journal 399 473-481.

Dyck D, Steinberg G \& Bonen A 2001 Insulin increases FA uptake and esterification but reduces lipid utilization in isolated contracting muscle. American Journal of Physiology. Endocrinology and Metabolism 281 E600-E607.

Farese R 2001 Insulin-sensitive phospholipid signaling systems and glucose transport. Update II. Experimental and Biological Medicine 226 283-295.

Farese R, Sajan M \& Standaert M 2005 Insulin-sensitive protein kinase (atypical protein kinase $\mathrm{C}$ and protein kinase $\mathrm{B} / \mathrm{Akt}$ ): actions and defects in obesity and type 2 diabetes. Experimental and Biological Medicine 230 593-605.

Gamble J \& Lopaschuk G 1997 Insulin inhibition of $5^{\prime}$ adenosine monophosphate-activated protein kinase in the heart results in activation of acetyl coenzyme A carboxylase and inhibition of fatty acid oxidation. Metabolism 45 1270-1274.

Gonzalez C \& Sanchez V 2006 Signaling mechanisms regulating lipolysis. Cellular Signaling 18 401-408.

Hajduch E, Alessi D, Hemmings B \& Hundal H 1998 Constitutive activation of protein kinase $\mathrm{B} \alpha$ by membrane targeting promotes glucose and system $\mathrm{A}$ amino acid transport, protein synthesis, and inactivation of glycogen synthase kinase 3 in L6 muscle cells. Diabetes 47 1006-1013.
Hashimoto T, Hussein R \& Brooks G 2006 Colocalization of MCT1, CD147, and LDH in mitochondrial inner membrane of L6 muscle cells: evidence of a mitochondrial lactate oxidation complex. American Journal of Physiology. Endocrinology and Metabolism 290 1237-1244.

Kelley D \& Mandarino L 2000 Fuel selection in human skeletal muscle in insulin resistance; a reexamination. Diabetes 49 677-683.

Kiens B, Kristiansen S, Jensen P, Richter E \& Turcotte L 1997 Membrane associated fatty acid binding protein (FABPpm) in human skeletal muscle is increased by endurance training. Biochemical and Biophysical Research Communication 231 463-465.

Klip A, Li G \& Logan W 1984 Induction of sugar uptake response to insulin by serum depletion in fusing L6 myoblasts. American Journal of Physiology. Endocrinology and Metabolism 10 E291-E296.

Koivisto U, Martinez-Valdez H, Bilan P, Burdett E, Ramlal T \& Klip A 1991 Differential regulation of the GLUT-1 and GLUT-4 glucose transport systems by glucose and insulin and insulin in L6 muscle cells in culture. Journal of Biological Chemistry 266 2615-2621.

Lin Y, Itani S, Kurowski T, Dean D, Luo Z, Yaney G \& Ruderman N 2001 Inhibition of insulin signaling and glycogen synthesis by phorbol dibutyrate in rat skeletal muscle. American Journal of Physiology. Endocrinology and Metabolism 281 E8-E15.

Luiken J, Dyck D, Han X, Tandon N, Arumugam Y, Glatz J \& Bonen A 2002 Insulin induces the translocation of the fatty acid transporter FAT/CD36 to the plasma membrane. American Journal of Physiology. Endocrinology and Metabolism 282 491-495.

Mitsumoto Y \& Klip A 1992 Developmental regulation of the subcellular distribution and glycosylation of GLUT 1 and GLUT 4 glucose transporters during myogensis of L6 muscle cells. Journal of Biological Chemistry 267 4957-4962.

Muoio D, Dohm G, Tapscott E \& Coleman R 1999 Leptin opposes insulin's effects on fatty acid partitioning in muscles isolated from obese ob/ob mice. American Journal of Physiology 276 E913-E921.

Palanivel R \& Sweeney G 2005 Regulation of fatty acid uptake and metabolism in L6 skeletal muscle cells by resistin. FEBS Letters $\mathbf{5 7 9}$ 5049-5054.

Raney MA \& Turcotte LP 2007 Evidence for the regulation of contractioninduced FA oxidation via ERK1/2 activation independent of changes in FA uptake. Metabolism 56 1192-1200.

Richter E, Hansen S \& Hansen B 1988 Mechanisms limiting glycogen storage in muscle during prolonged insulin stimulation. American Journal of Physiology. Endocrinology and Metabolism 255 621-628.

Saha A, Vavvas D, Kurowski T, Apazidis A, Witters L, Shafrir E \& Ruderman N 1997 Malonyl Co-A regulation in skeletal muscle: its link to cell citrate and the glucose-fatty acid cycle. American Journal of Physiology. Endocrinology and Metabolism 272 641-648.

Sajan M, Rivas J, Li P, Standaert M \& Farese R 2006 Repletion of atypical protein kinase $\mathrm{C}$ following RNA interference-mediated depletion restores insulin-stimulated glucose transport. Journal of Biological Chemistry 281 17466-17473.

Salteil A \& Kahn R 2001 Insulin signaling and the regulation of glucose and lipid metabolism. Nature 4 799-806.

Scheid M \& Woodgert J 2003 Unravelling the activation mechanisms of protein kinase B/Akt. FEBS Letters 546 108-112.

Shainberg A, Yagil G \& Yaffe D 1971 Alterations of enzymatic activities during muscle differentiation in vitro. Developmental Biology 25 1-29.

Sidossis LS \& Wolfe RR 1996 Glucose and insulin induced inhibition of fatty acid oxidation: the glucose fatty acid cycle reversed. American Journal of Physiology. Endocrinology and Metabolism 270 E733-E738.

Sidossis L, Coggan A, Gastaldelli A \& Wolfe R 1995 A new correction factor for use in tracer estimations of plasma fatty acid oxidation. American Journal of Physiology. Endocrinology and Metabolism 269 649-656.

Sinha S, Perdomo G, Brown N \& O'Doherty R 2004 Fatty acid-induced insulin resistance in $\mathrm{L} 6$ myotubes is prevented by inhibition of activation and nuclear localization of nuclear factor B. Journal of Biological Chemistry 279 41294-41301.

Somwar R, Sweeney G, Ramlal T \& Klip A 1998 Stimulation of glucose and amino acid transport and activation of the insulin signaling pathways by insulin lispro in L6 skeletal muscle cells. Clinical Therapentics 20 125-141. 
Taniguchi C, Kondo T, Sajan M, Luo J, Bronson R, Asano T, Farese R, Cantley L \& Kahn R 2006 Divergent regulation of hepatic glucose and lipid metabolism by phosphatidylinositol 3-kinase via Akt and PKC $\lambda / \zeta$. Cell Metabolism 3 343-353.

Tsakiridis T, McDowell H, Walker T, Downes P, Hundal H, Vranic M \& Klip A 1995 Multiple roles of phosphatidylinositol 3-kinase in regulation of glucose transport, amino acid transport, and glucose transport in L6 skeletal muscle cells. Endocrinology 136 4315-4322.

Tucker M \& Turcotte LP 2002 Impaired fatty acid oxidation in muscle of aging rats perfused under basal conditions. American Journal of Physiology. Endocrinology and Metabolism 282 E1109.

Turcotte LP, Swenberger J, Tucker M \& Yee A 1999 Training-induced elevation in FABPpm is associated with increased palmitate use in contracting muscle. Journal of Applied Physiology 87 285-293.

Turcotte LP, Swenberger J, Tucker M, Yee A, Trump G, Luiken J \& Bonen A 2002a Muscle palmitate uptake and binding are saturable and inhibited by antibodies to $\mathrm{FABP}_{\mathrm{PM}}$. Molecular and Cellular Biochemistry $21053-63$.

Turcotte LP, Swenberger J \& Yee A $2002 b$ High carbohydrate availability increases LCFA uptake and decreases LCFA oxidation in perfused muscle. American Journal of Physiology. Endocrinology and Metabolism 282 E177-E183.

Ueki K, Yamamoto-Honda R, Kaburagi Y, Yamauchi T, Tobe K, Burgering B, Coffer P, Komuro I, Akanuma Y, Yazaki Y et al. 1998 Potential role of protein kinase $\mathrm{B}$ in insulin-induced glucose transport, glycogen synthesis, and protein synthesis. Journal of Biological Chemistry 273 5315-5322.
Valverde A, Lorenzo M, Navarro P, Mur C \& Benito M 2000 Okadaic acid inhibits insulin-induced glucose transport in fetal brown adipocytes in an Akt-independent and protein kinase $\mathrm{C} \zeta$-dependent manner. FEBS Letters 472 153-158.

Vollenweilder P, Menard B \& Nicod P 2002 Insulin-resistance, defective insulin receptor substrate 2-associated phophatidylinositol- $3^{\prime}$ kinase activation, and impaired atypical protein kinase $\mathrm{C}(\zeta / \lambda)$ activation in myotubes from obese patients with impaired glucose tolerance. Diabetes 51 1052-1059.

Watt M, Steinberg G, Chen Z, Kemp B \& Febbraio M 2006 Fatty acids stimulate AMP-activated protein kinase and enhance fatty acid oxidation in L6 myotubes. Journal of Physiology 1 139-147.

Winder W \& Holmes B 2000 Insulin stimulation of glucose uptake fails to decrease palmitate oxidation in muscle if AMPK is activated. Journal of Applied Physiology 89 2430-2437.

Witters L \& Kemp B 1992 Insulin activation of acetyl-CoA carboxylase accompanied by inhibition of the $5^{\prime}$ AMPK-activated protein kinase. Journal of Biological Chemistry 267 2864-2867.

Yeh J, Gulve EA, Rameh L \& Birnbaum MJ 1995 The effects of wortmannin on rat skeletal muscle. Journal of Biological Chemistry 270 2107-2111.

Received in final form 11 May 2008

Accepted 14 May 2008

Made available online as an Accepted Preprint 14 May 2008 